\title{
Neurogenic T waves as clues for diagnosing hemorrhagic stroke
}

\author{
Ondas T neurogênicas como guias para diagnóstico de AVC hemorrágico \\ Wladimir Bocca Vieira de Rezende Pinto, Lucas Amorim Vieira de Barros, Paulo Victor Sgobbi de Souza, \\ José Luiz Pedroso, Orlando Graziani Povoas Barsottini
}

A 45-year-old female was brought with sudden loss of consciousness and mental confusion. Clinical background revealed obesity and hypertension. She presented with acute respiratory failures, hypertense and comatose without focal deficits. Serial ECGs disclosed dynamic ST segment changes and neurogenic $\mathrm{T}$ waves. Cranial CT evinced extensive intraparenchymal hemorrhage in left cerebral hemisphere (Figure).
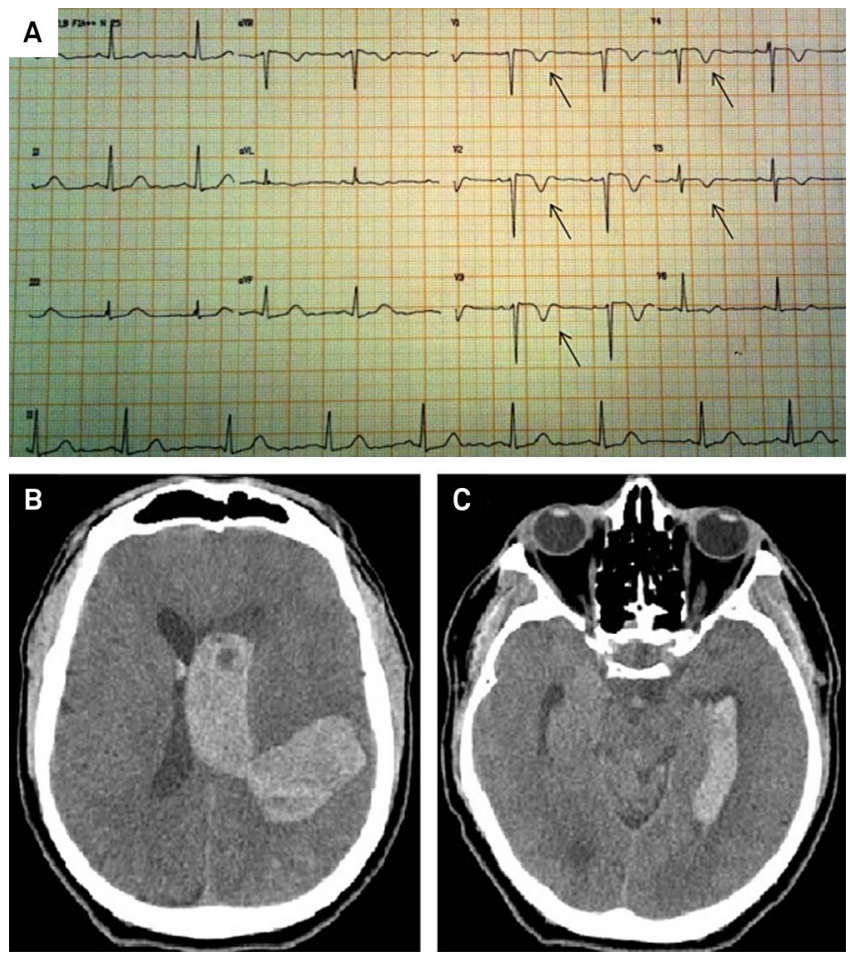

ST segment changes, QT prolongation and neurogenic or cerebral $\mathrm{T}$ waves are described in cerebrovascular events, generally related to subarachnoid and intracerebral hemorrhages $^{1,2}$, originated from central dysautonomia ${ }^{3}$. ECG changes may help differentiating causes of decreased level of consciouness without focal deficits, if cerebrovascular disorders are considered.

Figure. First 12-lead ECG showing diffuse precordial neurogenic $T$ waves (A - arrows). Cranial CT disclosing extensive intraparenchymal hemorrhage in left cerebral hemisphere with intraventricular extension and significant midline shift (B and $\mathrm{C}$ ).

1. Povoa R, Cavichio L, Almeida AL, et al. Electrocardiographic abnormalities in neurological diseases. Arq Bras Cardiol 2003;80(4):355-358.

2. Muehlschlegel S, Goddeau RP Jr., Sims JR Jr. Teaching neuroimage: cerebral T-waves from na aneurysmal cardunculus compression. Neurology 2008;70:28-29.

\section{3.}

Mandrioli J, Zini A, Cavazzuti M, Panzetti P. Neurogenic T wave inversion in pure left insular stroke associated with hyperhomocysteinaemia. J. Neurol Neurosurg Psychiatry 2004;75:1788-1789.

Departamento de Neurologia, Universidade Federal de São Paulo, Sao Paulo SP, Brazil.

Correspondence: Wladimir Bocca Vieira de Rezende Pinto; Rua Botucatu, 740; 04023-900 São Paulo SP, Brasil; E-mail: wladimirbvrpinto@gmail.com Conflict of interest: There is no conflict of interest to declare.

Financial disclosure: We have nothing to disclose.

Received 14 November 2013; Received in final form 03 February 2014; Accepted 24 February 2014. 